\title{
A REVOLUÇÃO DE 1930 NA ASSEMBLÉIA LEGISLATIVA E CĀMARA DE VEREADORES: ARROLAMENTO DE FONTES:
}

\author{
PROF. HARRY R. BELLOMO * \\ PROF. HARRY R. BELLOMO * \\ ACAD. EUGENIO CARLOS VASCONCELLOS ** \\ $A C A D$. JOSÉ L. M. NUNES **
}

\section{JUSTIFICATIVA:}

Transcorrendo este ano o cinqüentenário do movimento revolucionário de 1930 , iniciou-se em todo Brasil um grande movimento visando aprofundar e revisar os conhecimentos sobre este momento marcante da História nacional.

Incorporando-se a este processo o Departamento de História da PUC do Rio Grande do Sul, organizou um Simpósio sobre o tema Revolução de 1930.

Incorporando-nos este trabalho e visando suprir a tradicional falta de levantamentos de fontes primárias, nos propuzemos a fazer um trabalho de pesquisa neste sentido, levantando as fontes existentes nos anais do Conselho Municipal e Assembléia Legislativa no período de 1930 à 1936.

Alguns anos não aparecem no levantamento feito em virtude da dissolução dos Conselhos e Assembléias, logo após a vitória do movimento.

ARROLAMENTO DE FONTES PRIMĀRIAS NOS ANAIS DO CONSELHO MUNICIPAL DE PORTO ALEGRE - PERÍODO DE 1929 à 1935 -

ATA DA SESSÃO DE 11 de novembro de 1929.

Discurso de José Joaquim Seabra. Metas da Aliança Liberal.

ATA DA SESSÃO DE 18 de outubro de 1929.

Manifestacão de solidariedade a candidatura de Getúlio Vargas

ATA DA SESSĀO DE INSTALAÇÃO de 15 de outubro de 1930.

Ofício 816/45 do Intendente Municipal propondo a moçăo de solidariedade ao governo do Estado do Rio Grande do Sul ao apoiar a revolução redentora do Brasil.

Proposiçăo do conselho - Envio de telegrama ao dr. Getúlio Vargas, cumprimentando e hipotecando solidariedade. 
Leitura do programa do conselheiro dr. Camillo Martins da Costa agradecendo as congratulações dos colegas.

\section{ATA DA SESSÃO DE}

06.11. 1930

Telegrama do sr. dr. Getúlio Vargas, presidente provisório da república, agradecendo as efusivas congratulações recebidas deste conselho, recordando o apoio que sempre the foi prestado.

\section{ATA DA SESSÃO DE}

10.11.1930

Congratulou-se o Presidente do Conselho, com o regresso do dr. Camillo Martins Costa

O dr. Camillo agradeceu, respondendo, as generosas expressões do Conselheiro - Presidente, lamentou o afastamento da vida pública do notável tribuno dr. João Neves da Fontoura, solicita também que os órgãos representativos da Nação exprimam também o desejo de que este afastamento não se torne definitivo, através de um telegrama

\section{ATA DA SESSÃO DE}

\subsubsection{0}

Oficio 954 de 14.11.1930 do Secretário dos Negocios do Interior e do Exterior, que por ordem Presidente do Estado, que o Governo Provisório expedia o Decreto $\mathrm{n}^{\circ}$ 19.398, mandando dissolver o Congresso Nacional, as Assembléias Estaduais e os Conselhos Municipais, declarando extinto o mandato de seus Intendentes. Lido também radiograma do dr. João Neves de Fontoura, agradecendo as palavras do ConseIho enalteceu a sua obscura ação politica.

Após o Presidente enalteceu que o Conselho sempre soube corresponder a confiança dos municípios e que a dissolução do mesmo se tornaria necessária para que o Governo Provisório possa agir livremente no desempenho de sua missão.

\section{CONSELHO CONSULTIVO DE PORTO ALEGRE}

\section{A'TA DE INSTALAÇĀO}

\subsection{2 .1931}

Para instalação do Conselho Consultivo de Porto Alegre de conformidade com o Decreto ${ }^{\circ} 20.348$ de 29.08.31 do Governo Provisório da República.

\section{ATA DA SESSÃO DE} 28.04.1933

Telegramaao Exmo. dr. Getúlio Vargas, lamentando o acidente sofrido com votos de pronto restabelecimento.

\section{PARECERES}

Parecer do Conselho Consultivo sobre o orçamento da receita e despesa para $o$ ano de 1934. 
Tomada de contas do exercício de 1932 (Parecer do Conselho Consultivo). İtem ... Serviço da dívida.

Depósitos da Prefeitura para pagamento da divida Externa, conforme instruções do Governo Provisório.

Projeto de orçamento extraordinário para o exercício de 1.934 , apresentado pelo Major Alberto Bins, Prefeito Municipal.

Sobre o pagamento da divida externa dos poderes públicos, plano de reduçóes dos pagamentos da anuidades.

\subsubsection{4}

Parecer do Conselho Consultivo sobre o orçamento extraordinário para 1934. mico

Enaltece a administração do Governo Provisório sobre o reajustamento econô-

13.04.1934

Parecer do Departamento de Administração Municipal.

Sobre acordo realizado em 1931 complementar as medidas adotadas pelo Governo da República sobre as dividas externas

Projeto de orçamento ordinário para 1934 sobre o assunto anterior.

Parecer apresentado pelo Conselho ao projeto de orçamento ordinário para o exercício de 1934.

Sobre o mesmo assunto anterior

Projeto de orçamento para 1935, apresentado ao conselho pelo XI Prefeito Municipal.

Sobre o mesmo assunto anterior

Parecer do Conselho Consultivo sobre o projeto de orçamento de 1935.

Sobre a intenção do Governo Federal de cancelar os títulos adquiridos junto a Bolsa de N. York.

ATA DA SESSÃO DE

31.05.1935

Sobre o projeto de emissão de apólices de empréstimos a Prefeitura Municipal.

ATA DA SESSÃO

Da 2ªunião ordinária da Comissão Permanente em 30 de junho de 1936.

Parecer $n^{\circ} 4$

Sobre Poderes de Taxação entre a União e o Municipio. 
Sessão extraordinária da $2^{\text {a }}$ Reunião da Comissão Permanente em 5 de setembro de 1936.

Moção de apreço ao Parlamentar Dr. Antonio Carlos, iminente Presidente da Câmara Federal.

\title{
ATA DA $7^{\text {a }}$. SESSÃO
}

Sessão da $2^{\text {a }}$. Reunião ordinária da $1^{\text {a }}$. legislatura em 13 de outubro de 1936.

Voto de Pesar sobre o Pensamento do Cel. Antenor Amorim do Partido Republicano Liberal, com histórico de suas atividades em prol da Pátria.

\section{ATA DA $11^{a}$. SESSÃO}

Sessão da $2^{\text {a }}$. Reunião da $1^{\text {a }}$. legislatura, em 19 de Outubro de 1936.

O Prefeito Alberto Bins face as dificuldades econômicas do Estado e do funcionalismo público pede para baixar de 2:000\$000 para 1:000\$000 tal como era em 1935 .

\section{ATA DA $13^{a}$. SESSÃO}

Sessão da $2^{\text {a }}$. Reunião da $1^{\text {a }}$. legislatura, em 21 de Outubro de 1936.

A Câmara de Porto Alegre, reconhecendo como de alto valor patriótico a redução de vencimentos do Prefeito Municipal pedido por ele mesmo, entretanto indefere o pedido por julgar que nenhum servidor deve ter seus vencimentos dimunuidos.

(Parei na pg. $999-21^{\text {a }}$. Sessão da $2^{\text {a }}$. reunião ordinária da $1^{\text {a }}$. legislatura, em 3 de Novembro de 1936).

\section{ARROLAMENTO DE FONTES PRIMĀRIAS NOS ANAIS DA ASSEMBLËIA CONSTITUINTE. (1935)}

\section{ATA DA SESSÃO SOLENE DE POSSE DO $1^{\circ}$ GOVERNADOR CONSTITU- CIONAL 15/abril/1935}

Menção da indicação de Flores da Cunha para interventor.

\author{
ATA DA $16^{a}$. SESSÃO \\ 6/maio/1935
}

Causa fundamental da Revolução.

Discurso do deputado Fay de Azevedo.

ATA $25^{a}$. SESSÃO

$13 /$ maio/1935

Objetivos da Frente Única.

Discurso de Simões Lopes Filhn

ATA DA $26^{\circ}$. SESSÃO

16/maio/1935 
Causas da Revolução de 1930

Causas da crise da democracia.

Discurso de Rausl Pila.

\section{ATA DA $38^{\circ}$. SESSÃO}

$31 /$ maio/1935

Comentários sobre o decreto do governo provisório que aprovou os alunos por decreto.

Discurso de Aurélio Py.

\section{ATA DA SESSÃO SOLENE DE PROMULGAÇÃO DA CONSTITUIÇÃO 29/junho/1935}

Referências ao retorno da invocação a DEUS no preâmbulo da Constituição, por iniciativa do governo revolucionário.

Discurso de Roque Degrazia.

\section{ARROLAMENTO DE FONTES PRIMĀRIAS NOS ANAIS DA ASSEMBLÉIA LEGISLATIVA. ANO 1930}

ATA DA $11^{a}$. SESSÃO

$30 /$ setembro/ 1930

Referências a Aliança Liberal, Discurso de Getúlio Vargas

ATA $2^{\text {a }}$. SESSÃO

$2 /$ outubro/ 1930

Referências a Aliança Liberal, Partido Republicano e João Pessoa.

Discursos de Raul Bittencourt, Soeiro de Souza e Getúlio Vargas

ATA DA $4^{\text {a }}$. SESSĀO

7/outubro/1930

Referências as eleições e ao processo revolucionário em andamento

Discursos de João Machado, Raul Bitencourt e Paulo Hasslocher.

ATA DA $8^{\mathrm{a}}$. SESSÃO

11/outubro/1930

Medidas para empréstimos com finalidade de comprar material militar para a revolução

ATA DA SESSÃO DE

16/outubro/1930

Comunicação de que Getúlio Vargas seguiu para a zona de operações militares com o fito de assumiro comando das armas revolucionárias.

ATA DA $13^{\circ}$. SESSÃO

$24 /$ outubro/ 1930 
ATA DA $17^{a}$. SESSÃO

$6 /$ novembro/1930

Apoio a Getúlio Vargas

ATA DA $15^{a}$. SESSÃO

$30 /$ setembro/ 1930

Entrevista de Borges de Medeiros.

ATA DA $16^{a}$. SESSĀO

$7 /$ novembro/1930

Comentários sobre o discurso de Getúlio Vargas Análise da revolução.

ATA DA $19^{\circ}$. SESSÃO

$10 /$ novembro/ 1930

Renuncia de Getúlio ao cargo de Presidente do Estado

\section{ATA DA SESSÃO DE ENCERRAMENTO}

$21 /$ novembro/ 1930

Registro do decreto $n^{\circ} 19398$ de 11/11/30 Instituindo o Governo Provisório.

\section{ARROLAMENTO DE FONTES PRIMĀRIAS NOS ANAIS DA ASSEMBLÉIA} LEGISLATIVA - 1935 -

ATA DA $2^{a}$. SESSĀO

9/julho/1935

Análise da campanha leberal de 1920

Discurso de Raul Pila.

ATA DA $11^{a}$. SESSÃO

20/julho/1935

Discurso de Alberto de Britto sobre a questão social e manifesto de 1929.

ATA DA $16^{\circ}$. SESSÃO

27/julho/1935

Saudação do Partido Republicano Liberal a Flores da Cunha.

ATA DA $17^{\text {a }}$. e $18^{\text {a }}$. SESSÃO

$29 /$ julho e $30 /$ julho/1935

Pacificação do Rio Grande do Sul.

ATAS DA $30^{a}$. e $48^{a}$. SESSŌES

13/agosto/1935

4/setembro/1935 
Defesa de Borges de Medeiros.

Discursos de Camili Martins Costa e Aurélio Py.

ATA DA $67^{\circ}$. SESSĀO

4/outubro/1935

Discursos sobre quinto aniversário da revolução.
ATA DA $83^{\mathrm{a}}$. SESSÃO
24/outubro/1935

Discurso de Alberto de Britto sobre Getúlio Vargas.
ATA DA $109^{a}$. SESSĀO
$29 /$ novembro/ 1935

Análise do movimento comunista.

Relações do operariado e Getúlio Vargas

\begin{abstract}
ATA DA $110^{a}$. e $112^{a}$. SESSŌES
$30 /$ novembro/ 1935

4/dezembro/1935
\end{abstract}

Telegramas de Getúlio Vargas agradecendo o apoio recebido.

- Professor do Departamento de História PUCRS.

* * Alunos do Curso de Graduação em História PUCRS.

\title{
FONTES
}

1. Bibliografia da Assembléia Legislativa do Rio Grande do Sul. Livros de Atas.

1. Biblioteca da Assembléia Legislativa do Rio Grande do Sul. Livros de Atas.

2. Biblioteca da Câmara de Vereadores da Cidade de Porto Alegre. Livros de Atas.

3. Arquivo Histórico Municipal, Livros de Atas e de Pareceres. 